\title{
Accés als recursos en els sistemes agroforestals de l'Àfrica occidental des d'una perspectiva de gènere
}

\author{
Beatriz Salgado \\ Universitat Autònoma de Barcelona. Departament de Geografia \\ beatriz.salgado@gmail.com
}

Recepció: maig de 2012

Acceptació: desembre de 2012

\section{Resum}

L'article pretén estudiar, a partir de la recerca feta a la literatura publicada, de quina manera les poblacions rurals de l'Àfrica occidental gestionen i aprofiten els recursos dels ecosistemes on viuen. Tenint en compte la vulnerabilitat d'aquests sistemes de vida, l'accessibilitat i la titularitat sobre la terra, la vegetació, l'aigua i els cultius condicionen com es fa front als canvis que s'hi produeixen. En entorns on els ecosistemes estan fortament degradats, la mirada sobre les relacions que homes i dones estableixen amb el propi espai agrícola i forestal permet entendre mecanismes de resiliència de sistemes de vida i com enfocar possibles solucions a la desigualtat social i a la degradació ambiental. La dinàmica agrícola actual de compravenda de terres a escala mundial és una forta amenaça per a aquests sistemes de vida i posa de manifest la necessitat de modificar profundament les polítiques agrícoles per afrontar els reptes alimentaris i ambientals presents.

Paraules clau: Àfrica; gènere; accés i control sobre els recursos; medi ambient; sistemes de vida; titularitats.

Resumen. Acceso a los recursos en los sistemas agroforestales del África occidental desde una perspectiva de género

El artículo pretende estudiar, a partir de la investigación en la literatura publicada, de qué manera las poblaciones rurales de África occidental gestionan y aprovechan los recursos de los ecosistemas donde viven. Teniendo en cuenta la vulnerabilidad de estos sistemas de vida, la accesibilidad y la titularidad sobre la tierra, la vegetación, el agua y los cultivos condicionan el modo de hacer frente a los cambios que se producen. En entornos donde los ecosistemas están altamente degradados, la mirada sobre las relaciones que hombres y mujeres establecen con el propio espacio agrícola y forestal permite entender los mecanismos de resiliencia de los sistemas de vida y cómo enfocar posibles soluciones a la desigualdad social y a la degradación ambiental. La dinámica agrícola actual de compraventa de tierras a escala mundial es una fuerte amenaza para estos sistemas de vida y pone de manifiesto la necesidad de modificar profundamente las políticas agrícolas para afrontar los retos alimentarios y ambientales presentes.

Palabras clave: África; género; acceso y control sobre los recursos; medio ambiente; sistemas de vida; titularidades. 
Résumé. Accès aux ressources dans les systèmes agroforestiers de l'Afrique occidentale d'une perspective de genre

L'article essaie d'étudier, à partir de la recherche de la littérature publiée, de quelle manière les populations rurales de l'Afrique de l'ouest gèrent et profitent les ressources des écosystèmes où elles habitent. Compte tenu de la vulnérabilité de ces systèmes de vie, l'accessibilité et le droit à la libre disposition à la terre, la végétation, l'eau, les cultures, sont clés pour comprendre comment les populations font face aux changements qui se produisent. Dans des entourages où les écosystèmes sont fortement dégradés, le regard sur les relations qu'hommes et femmes établissent avec leur espace agricole et forestier permet de comprendre les mécanismes de résilience de ces systèmes de vie et comment aborder des possibles solutions à l'inégalité sociale et à la dégradation environnementale. La dynamique agricole actuelle d'achat et vente de terres à échelle mondiale est une forte menace pour ces systèmes de vie et met en évidence la nécessité de modifier profondément les politiques agricoles pour affronter les défis alimentaires et environnementales présents.

Mots clé: Afrique; genre; accès et contrôle sur les ressources; environnement; moyens de subsistance; droit à la libre disposition.

\section{Abstract. Access to resources in West Africa agroforestry systems from a gender perspective}

The article tries to study, through the survey of the published literature, how the rural populations in West Africa manage and take advantage of the resources in the ecosystems where they live. Accounting of the vulnerability of these livelihoods, the accessibility and entitlement over land, vegetation, water, crops condition how these populations cope with the changes that occur. In highly deteriorated environments, the gaze at the relationships that men and women establish with their own agricultural and forest space helps to understand the resilience mechanisms of these livelihoods and how to address possible solutions to social inequality and environmental degradation. The current dynamic of landgrabbing throughout the world is a serious threat to these livelihoods and exposes the need to deeply modify agricultural policies to face the present food and environmental challenges.

Keywords: Africa; gender; access and control over resources; environment; livelihoods; entitlements.

\section{Sumari}

1. Introducció: objectiu, context i metodologia

2. Marc teòric

3. Resultats
4. Reflexions sobre la perspectiva de gènere a l'Àfrica

5. Conclusions

6. Referències bibliogràfiques

\section{Introducció: objectiu, context i metodologia}

Les pràctiques agroforestals que combinen arbres i cultius són la base dels sistemes de vida dels petits agricultors i agricultores. Els arbres constitueixen un component essencial dels sistemes agrícoles de l'Àfrica occidental, on són deliberadament seleccionats i mantinguts. Durant el procés de selecció, algu- 
nes espècies són eliminades i unes altres, conservades, segons la funcionalitat que presentin per proveir menjar, medicina, fusta, combustible o algun altre servei ambiental.

Avui dia, ens enfrontem a una triple crisi mediambiental: la crisi climàtica, la crisi energètica i la crisi alimentària. Aquestes alteracions ambientals d'origen antròpic afecten el conjunt de la biodiversitat i els usos del sòl a tot el planeta. L'accelerament de la mecanització a través de la implantació creixent de l'agricultura industrial provoca un agreujament de la inseguretat alimentària local i global. El fenomen de l'acaparament de terres que està tenint lloc arreu del món en els últims anys provoca un desplaçament generalitzat de comunitats rurals i periurbanes, especialment petits agricultors i agricultores. Les dones són les agricultores de subsistència del planeta. La terra és la base material del treball de subsistència femení, que ha estat la principal font de seguretat alimentària per a milions de persones de tota la Terra. La relació que s'estableix entre els homes, les dones i els ecosistemes on viuen, a través dels rols socials, els drets i les oportunitats diferenciats, és al centre de la recerca.

A partir de la literatura existent, aquest article vol donar resposta a les preguntes: De quina manera diferenciada homes i dones accedeixen als recursos naturals i els controlen? Com l'ús d'aquests recursos transforma diferents components dels ecosistemes i dels propis sistemes de vida? De quina manera el coneixement sobre els sistemes de vida de les poblacions de l'Àfrica occidental permet trobar respostes als desafiaments mediambientals i socials del segle XXI?

Per tal d'analitzar les interrelacions de les societats rurals africanes amb el medi ambient, els seus condicionants i vulnerabilitats, la recerca s'ha basat en l'estudi de fonts secundàries a partir d'articles de revista, principalment. Per tal de dur a terme l'anàlisi, s'han revisat revistes especialitzades de geografia, revistes enfocades a la temàtica d'economia i desenvolupament, revistes enfocades a la temàtica de gènere i revistes especialitzades en el continent africà. El marc temporal de les cerques correspon al període que va de l'any $1990 \mathrm{al}$ 2011. A la taula 1, s'hi enumeren les revistes consultades, classificades segons si s'hi han trobat resultats rellevants o no.

De cada grup de revistes, se n'ha escollit una sèrie de paraules clau ${ }^{1}$, a fi de realitzar la cerca simple o avançada, segons els casos.

La cerca bibliogràfica ha permès seleccionar 26 articles rellevants per a l'objectiu plantejat. De les revistes que han publicat algun text sobre la temàtica estudiada, la presència d'articles es força desequilibrada, com es mostra a la taula 3. Les revistes de temàtica econòmica i sobre desenvolupament són les que més articles concentren, amb el 50\% del total. A la la revista World Development és on n'hi ha més. Seguidament, tindríem les revistes sobre Àfrica, amb un $27 \%$ del total. Finalment, trobem les revistes sobre geografia i sobre gènere, amb un $11,5 \%$ del total d'articles a cadascun dels grups. A la taula 3 ,

1. La majoria de revistes són anglòfones. Les paraules clau utilitzades són una traducció de les del text original. 
Taula 1. Revistes consultades

\begin{tabular}{ll}
\hline Revistes sense resultats rellevants & Revistes amb resultats rellevants \\
\hline Revistes generals de geografia & \\
Antipode & Geoforum \\
Area & Global Environmental Change \\
Progress in Human Geography & Cahiers de Géographie du Québec \\
Social and Cultural Geography & \\
Annals of the Association of American & \\
$\quad$ Geographers & \\
Environment and Planning: Society and Space & \\
Anales de Geografía de la Universidad & \\
Complutense & \\
Boletín de la Asociación de Geógrafos & \\
Españoles & \\
Documents d'Anàlisi Geogràfica & \\
Treballs de la Societat Catalana de Geografia &
\end{tabular}

Revistes sobre economia i desenvolupament Journal of Rural Studies

World Development

Gender, Technology and Development

Development in Practice

American Journal of Agricultural Economics

Journal of Agrarian Change

International Journal of Social Welfare

Environment, Development and Sustainability

Land Use Policy

Feminist Economics

Revistes sobre gènere

Gender, Technology and Development

Gender, Place and Culture

Bi-Annual Journal for Women International

Feminist Economics

Revistes sobre Àfrica

Africa Insight

Africa

African Studies

Canadian Journal of African Studies

Cahiers d'Études Africaines

Journal of Asian and African Studies

Journal of Contemporary African Studies

Studia Africana

Nova Africa

Nordic Journal of African Studies

Font: elaboració pròpia.

Taula 2. Combinacions de paraules-clau per tipus de revista

\begin{tabular}{ll}
\hline Tipus de revista & Combinacions de paraules clau \\
\hline Revistes generals sobre geografia & gènere i Àfrica; dona i Àfrica. \\
Revistes sobre economia i desenvolupament & gènere i Àfrica; dona i Àfrica. \\
Revistes sobre gènere & Àfrica. \\
Revistes sobre Àfrica & gènere; dona; mediambient; terra; aigua; llenya; \\
& transport; mobilitat. \\
\hline
\end{tabular}

Font: elaboració pròpia. 
Taula 3. Distribució dels articles segons la tipologia de les revistes seleccionades

\begin{tabular}{lcc}
\hline Títol de la revista & Nombre d'articles & $\%$ \\
\hline Revistes generals sobre geografia & 3 & 100 \\
Geoforum & 1 & 33,3 \\
Global Environmental Change & 1 & 33,3 \\
Cahiers de Géographie du Québec & 1 & 33,3 \\
\hline Revistes sobre economia i desenvolupament & 14 & 100,0 \\
World Development & 8 & 57,1 \\
Development in Practice & 1 & 7,1 \\
Journal of Agrarian Change & 2 & 14,3 \\
Environment, Development and Sustainability & 1 & 7,1 \\
Land Use Policy & 1 & 7,1 \\
Feminist Economics & 1 & 7,1 \\
\hline Revistes sobre gènere & 3 & 100,0 \\
Gender, Place and Culture & 1 & 33,3 \\
Bi-Annual Journal for Women International & 1 & 33,3 \\
Feminist Economics & 1 & 33,3 \\
\hline Revistes d'Àfrica & 7 & 100,0 \\
Africa & 1 & 14,3 \\
Canadian Journal of African Studies & 1 & 14,3 \\
Journal of Asian and African Studies & 2 & 28,6 \\
Studia Africana & 2 & 28,6 \\
Nordic Journal of African Studies & 1 & 14,3 \\
\hline Total (amb 1 repetició) & 27 & \\
\hline
\end{tabular}

Font: elaboració pròpia.

s'hi pot apreciar la distribució dels articles per revista. Cal mencionar que el nombre total d'articles és 26, però que el publicat a la revista Feminist Economics ha estat comptat dues vegades, ja que el podem classificar a la categoria d'economia i desenvolupament, però també a la de gènere.

És important tenir present que la periodicitat i l'extensió de totes les revistes no és la mateixa. Per això, les comparacions fetes només pretenen ser orientatives.

Quan estem tractant d'entendre les relacions i les interrelacions entre homes i dones i el medi ambient on viuen, estem estudiant relacions complexes i dinàmiques. Aquestes relacions, en molts casos, no es poden mesurar, sinó que s'han d'entendre (Moller Madsen i Adriansen, 2004). Així, els articles que s'han seleccionat són aquells que contenen informació de camp que permet contextualitzar els resultats i el treball sobre realitats concretes. L'objectiu no ha estat sistematitzar tots els treballs de camp sobre la matèria, tasca impossible per a aquesta recerca, sinó elaborar, a partir de casos d'estudi de diferents comunitats a diversos països, un panell de rellevàncies i de conflictes, així com de maneres diferents d'aproximar-se a l'ús de l'espai rural i l'accés als recursos. 
Per tal d'ampliar el nombre de referències estudiades, s'han incorporat a l'anàlisi 9 capítols de llibres, així com 4 treballs presentats en dos congressos recents $^{2}$ i en un congrés més antic ${ }^{3}$. Això suposa un total de 39 referències.

\section{Marc teòric}

El marc teòric es basa en quatre marcs conceptuals diferents que es complementen per tal d'entendre de quina manera l'accés als recursos a l'Àfrica occidental condiciona i està condicionat per una gestió adaptativa al medi ambient, des de la perspectiva d'actors socials diferenciats.

El concepte serveis dels ecosistemes, que data de la dècada de 1970, torna a prendre rellevància a la dècada de 1990 (Costanza et al., 1997). L'Avaluació dels Ecosistemes del Mil.lenni (2003, 2005) categoritza en quatre grups els serveis que la població humana obté dels ecosistemes: els serveis de provisió (com ara el menjar, l'aigua, la llenya); els serveis de regulació (de clima, d'aigua, de malalties); els serveis culturals (estètics, de lleure), i els serveis de suport (necessaris per obtenir els altres, com ara el cicle dels nutrients o la formació de sòls). Com que la part social i la part ecològica no es poden separar, ja que es retroalimenten en un canvi constant, l'estudi dels ecosistemes ha anat evolucionant cap a l'estudi dels sistemes socioecològics (Chelleri i Breton, 2010). Així, és la capacitat de fer front als canvis i de ser capaços d'adaptar-se, tractant de configurar un nou equilibri, el que esdevé d'una importància vital per als sistemes de vida. És el que s'anomena resiliència dels sistemes socioecològics.

Un segon enfocament és el que estudia la relació entre la dona i el medi ambient. L'aproximació biològica vincula la natura amb la feminitat com una relació essencial (Agarwal, 1991), on l'home representa la cultura i la dona, la natura. Una segona aproximació al terme critica aquest enfocament universalista per dotar-lo del component històric dintre d'un ordre social donat. Així, l'origen de les relacions que homes i dones mantenen amb l'entorn resideix en les funcions socialment assignades a cadascun dels gèneres. La reproducció social i la cura del grup familiar condicionen que siguin les dones les que tinguin un contacte més directe amb els recursos naturals (aigua, sòls, boscos), especialment en sistemes econòmics de subsistència (Sabaté, 2000). Aquesta teoria va en la línia de l'ecologia política feminista, que tracta el gènere com una variable que determina l'accés i el control dels recursos, interactuant amb l'edat, la classe social, l'ètnia en els processos de canvi ecològic (Momsen, 2004).

2. Es tracta del 7è Congrés Ibèric sobre Estudis Africans realitzat a Lisboa (Portugal), el mes de setembre de 2010, i de The International Conference on Global Land Grabbing, realitzada a Brighton (Regne Unit), el mes de maig de 2011.

3. Correspon a la tercera conferència de la Xarxa Oest Africana sobre Tracció Animal que va tenir lloc a Senegal l'any 1988. La referència es va trobar a través de The African Studies Centre, radicat a Leiden (Holanda), que ha desenvolupat un cercador de bibliografia sobre literatura femenina africana. 
L'enfocament dels sistemes de vida (livelihoods approach) aprofundeix en la comprensió de les dinàmiques rurals i el seu desenvolupament. Es parteix del concepte ecologisme dels pobres, que neix a finals de la dècada de 1980 per explicar els conflictes en què els pobres defensen el medi ambient enfront de l'estat o del mercat. Martínez-Alier (2002) afirma que es tracta d'un ecologisme dels sistemes de vida basat tant en la preservació de la seguretat econòmica que dóna la participació en els mercats locals, com en l'accés als recursos i als serveis ambientals fora del mercat. Un sistema de vida està considerat sostenible quan pot fer front a un xoc, recuperar-se i mantenir o millorar les capacitats i els actius, tant avui com en el futur, sense malmetre la base de recursos (Carney, 1996).

L'últim enfocament que cal tenir en compte és el de titularitats mediambientals (Leach et al., 1999), basat en la teoria de les titularitats dels aliments d'Amartya Sen (1981), que estan compostes pels mecanismes dels quals disposen les persones per accedir i utilitzar els recursos naturals, com poden ser les pastures comunitàries o les fonts naturals d'aigua. Aquest enfocament estudia de quina manera les dinàmiques ecològiques $i$ socials influeixen en les activitats de gestió dels recursos naturals de diversos grups de persones i que, a la vegada, permeten produir i articular diferents tipus d'ambients particulars. En comptes de veure els problemes mediambientals en termes de pressió de la població agregada sobre un recurs limitat, l'enfocament de les titularitats considera el rol de les diferents institucions, formals i informals, en les relacions dels diferents actors sobre el medi ambient.

Aquests quatre elements principals (resiliència dels sistemes socioecològics, gènere i medi ambient, sistemes de vida i titularitats ambientals) són els que conformen el marc teòric. A la taula 4 , s'hi presenten de manera esquemàtica les interrelacions principals entre els diferents enfocaments.

Taula 4. Interrelacions entre els diferents enfocaments teòrics

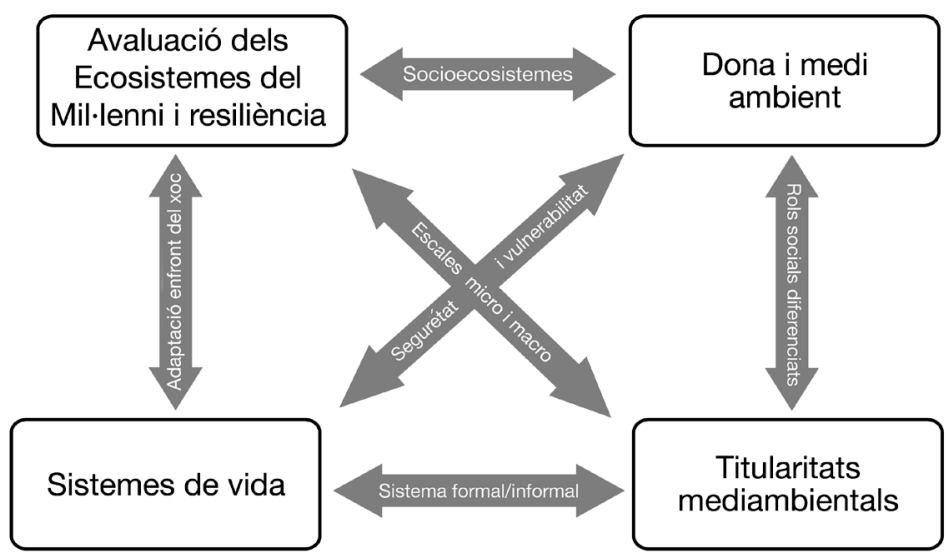

Font: elaboració pròpia. 


\section{Resultats}

A les cerques realitzades, s'hi han trobat 39 referències rellevants, entre articles de revista, capítols de llibre i comunicacions presentades a congressos. A part dels articles rellevants a la zona d'estudi, se n'hi han integrat uns altres que engloben tota l'África subsahariana, perquè són pertinents per a la recerca. Dels quinze països que formen l'África occidental, n'hi ha tres que no hi estan representats: Cap Verd, Libèria i Togo. Hi ha cinc repeticions: Awumbila i Momsen (1995), que centren la seva recerca tant a Burkina Faso com a Ghana; Carney i Elias (2006), que analitzen tota l'Àfrica occidental i donen exemples, tant de Ghana com de Mali; Milano (2010), que ho fa de Guinea Bissau i Mali; Bunch (2010), que parla generalment de l'Àfrica subsahariana i posa algun exemple sobre Mali, i, finalment, Hilhorst et al. (2011), que duen a terme estudis de cas a Benín, Burkina Faso i Níger.

La integració dels quatre enfocaments teòrics permet presentar els resultats segons tres eixos: el medi ambient, les titularitats en els sistemes de vida i el paper de les institucions. A continuació, mostrem la classificació dels articles en funció de la categoria temàtica dintre de cada eix. N'hi ha que estan inclosos en més d'una categoria.

L'apartat d'una diagnosi adequada vol deixar constància de la importància d'una bona diagnosi a l'hora de pal.liar els problemes d'accessibilitat als recur-

Taula 5. Localització dels articles seleccionats per països

\begin{tabular}{|c|c|c|}
\hline País & Nombre d'articles & Autoria \\
\hline Àfrica occidental & 3 & $\begin{array}{l}\text { Adams et al., 1999; Carney et al., 2006; Hossein, } \\
2004 .\end{array}$ \\
\hline Àfrica subsahariana & 19 & $\begin{array}{l}\text { Bromley et al., 2008; Bunch, 2010; Cortabitarte, } \\
\text { 1994; Evers et al., 2000; Federici, 2004; Gibson, } \\
\text { 2004; Halweil et al., 2010; Jiggins, 1989; Joireman, } \\
\text { 2008; Mackenzie, 1993; Meinzen-Dick et al., 1997; } \\
\text { Oberhauser, 2004; Postel, 2010; Pretty, 1999; } \\
\text { Razavi, 2003; Reij, 2010; Rocheleau et al., 1997; } \\
\text { Whitehead et al., 2003; Woodhouse et al., } 2011 .\end{array}$ \\
\hline Benín & 2 & Agúndez et al., 2010; Hilhorst et al., 2011. \\
\hline Burkina Faso & 4 & $\begin{array}{l}\text { Awumbila et al., 1995; Carney et al., 2004; } \\
\text { Gray et al., 1999; Hilhorst et al., } 2011 .\end{array}$ \\
\hline Gàmbia & 1 & Schroeder et al., 1996. \\
\hline Ghana & 5 & $\begin{array}{l}\text { Awumbila et al. 1995; Bryceson et al., 1993; } \\
\text { Carney et al., 2006; Leach et al. 1999; Porter, } 2002 .\end{array}$ \\
\hline Guinea & 1 & Laakso et al., 2006. \\
\hline Guinea Bissau & 1 & Milano, 2010. \\
\hline Mali & 3 & Bunch, 2010; Carney et al., 2006; Milano, 2010. \\
\hline Níger & 2 & Hilhorst et al., 2011; Letty et al., 2010. \\
\hline Nigèria & 1 & Ekejiuba, 1995. \\
\hline Senegal & 2 & Nelson-Fyle et al., 1990; Sow, 2000. \\
\hline Sierra Leone & 2 & Leach, 1992, 1994. \\
\hline Total (amb repeticions) & 46 & \\
\hline
\end{tabular}

Font: elaboració pròpia. 
Taula 6. Classificació temàtica dels articles seleccionats

\begin{tabular}{|c|c|c|}
\hline Temes & Nombre d'articles & Autoria \\
\hline Una diagnosi adequada & 3 & $\begin{array}{l}\text { Halweil et al., 2010; Hossein, 2004; } \\
\text { Jiggins, } 1989 .\end{array}$ \\
\hline El medi ambient & 14 & \\
\hline La fertilitat del sòl & 3 & $\begin{array}{l}\text { Bunch, 2010; Halweil et al., 2010; } \\
\text { Reij, } 2010 .\end{array}$ \\
\hline L'aigua & 3 & $\begin{array}{l}\text { Halweil et al., 2010; Postel, 2010; } \\
\text { Sow, } 2000 .\end{array}$ \\
\hline Els boscos i la desforestació & 4 & $\begin{array}{l}\text { Cortabitarte, 1994; Laakso et al., } \\
\text { 2006; Leach, 1992, } 1994 .\end{array}$ \\
\hline Els paisatges ecoagrícoles & 4 & $\begin{array}{l}\text { Agúndez et al., 2010; Halweil et al., } \\
\text { 2010; Milano, 2010; Pretty, } 1999 .\end{array}$ \\
\hline $\begin{array}{l}\text { Les titularitats en els sistemes } \\
\text { de vida }\end{array}$ & 22 & \\
\hline La cosmovisió & 2 & Sow, 2000; Carney, 2006. \\
\hline Els espais femenins i masculins & 12 & $\begin{array}{l}\text { Agúndez et al., 2010; Awumbila } \\
\text { et al., 1995; Carney et al. 2004, 2006; } \\
\text { Federici, 2004; Gibson 2004; Gray } \\
\text { et al., 1999; Leach, 1992, 1994; } \\
\text { Rocheleau et al., 1997; Shroeder } \\
\text { et al., 1996; Sow, } 2000 .\end{array}$ \\
\hline Les estratègies de subsistència & 4 & $\begin{array}{l}\text { Adams et al., 1998; Carney et al., } \\
\text { 2004, 2006; Laakso et al., } 2006 .\end{array}$ \\
\hline Els mitjans de transport & 4 & $\begin{array}{l}\text { Bryceson et al., 1993; Evers et al., } \\
\text { 2000; Nelson-Fyle et al., 1990; } \\
\text { Porter, } 2002 .\end{array}$ \\
\hline El paper de les institucions & 18 & \\
\hline $\begin{array}{l}\text { Institucions informals com } \\
\text { a factors endògens }\end{array}$ & 7 & $\begin{array}{l}\text { Adams et al., 1998; Bromley, 2008; } \\
\text { Gray et al. 1999; Letty et al., 2010; } \\
\text { Ekejiuba, 1995; Oberhauser et al., } \\
\text { 2004; Razavi, 2003. }\end{array}$ \\
\hline $\begin{array}{l}\text { Institucions formals com } \\
\text { a factors exògens }\end{array}$ & 11 & $\begin{array}{l}\text { Adams et al., 1998; Awumbila et al., } \\
\text { 1995; Bromley, 2008; Halweil et al., } \\
\text { 2010; Hilhost et al., 2011; Joireman, } \\
\text { 2008; Mackenzie, 1993; Milano, 2010; } \\
\text { Razavi, 2003; Whitehead et al., 2003; } \\
\text { Woodhouse et al., } 2011 .\end{array}$ \\
\hline
\end{tabular}

Total (amb repeticions) 57

Font: elaboració pròpia.

sos, tot posant de manifest que no existeixen solucions úniques ni fórmules màgiques. A continuació, presento un resum dels resultats més importants trobats a cadascun dels eixos principals.

\section{El medi ambient}

Aquest eix engloba les referències que tracten dels canvis ecològics que afecten la configuració de les titularitats. Les referències més abundants tenen a veure 
amb la forta degradació dels ecosistemes africans, sobretot en relació amb els sòls, els boscos i les fonts d'aigua.

La producció total d'aliments s'està mantenint malgrat la pèrdua de fertilitat del sòl. Això provoca uns rendiments decreixents de la terra. Per als agricultors de subsistència de l'Àfrica, que majoritàriament cultiven blat de moro, melca, mill i tubercles, la generació tradicional de compost requereix molta feina. Així mateix, el fertilitzant químic, encarit per la fi de les subvencions i l'increment del preu del petroli, tampoc és cap solució, ja que els costos també superen l'increment de rendiment (Bunch, 2010; Halweil i Nierenberg, 2010).

Una possible solució són els cultius de cobertura per millorar la fertilitat del sòl i controlar les males herbes. Aquests cultius poden reduir fortament les tasques de desherbatge que duen a terme principalment les dones (Bunch, 2010). Es tracta de conrear plantes i arbres que produeixen moltes fulles i així rejovenir la terra.

Això també té uns altres impactes socials i ambientals molt positius a curt termini, importantíssims per regenerar la terra desforestada. La conservació deliberada d'arbres disseminats sobre les terres cultivades o en guaret proporciona molts beneficis, tant directament per al consum a la llar (Reij, 2010), com per obtenir ingressos de la venda directa o de la transformació dels productes (nous de karité, llavors de néré, nous d'anacard, mangos) als mercats locals (Agúndez et al., 2010).

Així, exemples trobats arreu de l'Àfrica occidental mostren com les pràctiques ecoagrícoles incrementen la productivitat de la terra, el treball i el capital, $\mathrm{i}$, alhora, redueixen les necessitats d'aigua, com també de fertilitzants sintètics, pesticides, herbicides $i$, sovint, mà d'obra, sobretot pel que respecta a tasques realitzades per les dones, ja que estan pensades per satisfer múltiples objectius socials, ecològics i econòmics (Pretty, 1999).

\section{Les titularitats en els sistemes de vida}

Quan es tracta d'arbres, boscos, cultius i animals, les dicotomies existents, entre l'home que posseeix la terra i la dona que no la posseeix, desapareixen per donar pas a una imbricació complementària en l'ús, el control i la propietat formal dels recursos. Aquesta forma de tinença dels recursos es caracteritza per la complexitat i la multidimensionalitat que presenta (Rocheleau i Edmunds, 1997). El règim de tinença sobre els boscos i els arbres es pot analitzar a través de l'activitat, la titularitat i l'autoritat de dones i homes en espais determinats.

Aquests espais no tenen res a veure amb la tinença formal sobre els recursos, ja que es tracta de drets de facto basats en les lleis tradicionals i en les pràctiques diàries. Quan es tracta d'espais comuns, també existeix certa separació sobre les plantes o els animals als quals pot accedir cadascú. A moltes parts d'Àfrica occidental, les dones tenen drets ben definits sobre els fruits, les branques seques $i$ les fulles dels arbres dels homes. L'accés també varia durant l'any. Els arbres farratgers i els arbustos controlats pels homes en estació seca poden alimentar el bestiar de les dones en estació humida (Shroeder i Krisnawati, 1996). 
Aquestes divisions expressen la complementarietat del control i la gestió sobre els recursos. Aquests acords, això no obstant, també poden reflectir el fet que els espais, les plantes, els animals i els productes femenins són les restes, el que queda darrere o abandonat en el paisatge, la qual cosa mostra el rol secundari de les dones enfront de la importància de les activitats masculines. Així, les relacions que s'estableixen sobre els diferents tipus de tinença depenen de les condicions ecològiques i socials canviants, cosa que obliga dones i homes a renegociar constantment els termes de l'accés als diferents recursos (Leach, 1992 i 1994; Gray i Kevane, 1999; Carney i Elias, 2004 i 2006; Agúndez et al., 2010).

En aquest context, Adams et al. (1998) pretenen fer reflexionar sobre la manera com les llars rurals, empobrides i vulnerables, fan front als moments de crisi. Es tracta de parar atenció a l'escala temporal. El consum d'aliments és un objectiu secundari per tal de preservar la base productiva de la llar. La malnutrició s'ha de veure no solament com el fracàs de l'estratègia de subsistència, sinó també com un dels costos que comporta (Adams et al., 1998: 267). D'aquí sorgeix la idea d'elecció, de trade-off. Mentre que la recollida controlada de llenya per vendre pot representar una bona estratègia a curt termini per assegurar el consum i el sistema de vida de la llar, l'abús d'aquesta estratègia pot provocar impactes ecològics i econòmics negatius importants si s'impedeix que els recursos del bosc es regenerin naturalment.

En el context de dificultat en les condicions rurals femenines, Federici (2004) presenta un context femení de defensa constant de la producció de subsistència. Elles lluiten per evitar la tala comercial i salvar els boscos, fonaments de les economies de subsistència i proveïdors d'aliment, energia i relacions comunals. La producció de subsistència de les dones contraresta la tendència de l'agroindústria de reduir les seves terres de cultiu. Elles controlen la qualitat dels aliments i protegeixen els consumidors enfront de la manipulació dels cultius. Aquesta activitat femenina es torna cada vegada més visible (Gibson, 2004).

Per tal que les comunitats vegin disminuir la vulnerabilitat dels seus sistemes de vida, l'accés a infraestructures de transport esdevé essencial. Quan es tracta d'analitzar el paper diferenciat de les dones africanes com a proveïdores de la seguretat alimentària familiar, pren una rellevància especial el rol que tenen en el transport rural. Una reducció en el temps de transport i en l'esforç femení podrien ser redirigits a millorar la productivitat agrícola i el benestar de la unitat familiar (Bryceson i Howe, 1993; Evers i Walters, 2000).

\section{El paper de les institucions}

Els sistemes de vida i les estratègies per fer front a les crisis no són fixos, ni genèrics, entre les llars, sinó que varien en funció del context endogen i exogen de la pròpia llar. Les institucions informals corresponen als factors endògens $\mathrm{i}$ les institucions formals, als exògens. Les referències als factors de canvi endogen corresponen a aquells elements que afavoreixen l'empoderament femení i la 
seva visibilitat dintre de la llar i la comunitat (Ekejiuba, 1995; Oberhauser et al., 2004; Letty et al., 2010).

L'accés desigual a la terra per part de les dones és considerat un mecanisme important a través del qual es reprodueixen la pobresa femenina i la subordinació. La literatura estudiada porta a debatre sobre la gestió dels béns comuns. La visió neoliberal basada en la tragèdia dels comuns de Hardin (1968) i que advoca per l'assignació de drets de propietat a les dones per tal de millorar el seu poder de negociació dintre de la llar es veu fortament criticada pels qui entenen la multiplicitat d'interessos i tinences en una mateixa parcel.la característica de les zones rurals africanes (Bromley, 2008; Joireman, 2008). Diversos membres de la família (o de la comunitat) tenen drets reconeguts socialment sobre diferents productes de la mateixa parcel.la: un individu pot conrear certs cultius; un altre, recollir llenya; inclús un altre pot obtenir farratge de la mateixa parcel.la. És en aquest sentit que es defensa la propietat comunal entesa com la gestió dels béns comuns teoritzada per Ostrom (1990). La definició de drets de propietat formals per a les dones no les durà automàticament a tenir garantides les demandes sobre els recursos de subsistència. Segons Razavi (2003) i Whitehead i Tsikata (2003), l'assignació de drets de propietat provoca uns resultats que queden lluny de l'equitat social.

Més enllà de les normes i dels acords informals d'assignació de recursos a la llar i a la comunitat, les institucions formals tenen un paper molt important a l'hora d'establir el grau de llibertat i els drets individuals i col-lectius (Gray i Kevane, 1999).

Els programes d'ajustament estructural de la dècada de 1980, que van consistir en la transformació productiva de les economies endeutades orientantles a l'exportació de matèries primeres i productes agrícoles, van exercir uns efectes molt nocius sobre el medi ambient (Cortabitarte, 1994; Mackenzie, 1993; Milano, 2010), així com sobre les economies locals, a causa de la pèrdua d'autonomia i d'identitat cultural (Milano, 2010), i va incrementar les desigualtats de gènere (Awumbila i Momsen, 1995). Aquests programes han estat criticats àmpliament, però la liberalització econòmica que impera des d'aleshores és la que facilita l'onada de compra de terres que està tenint lloc arreu del món des de l'any 2008 per part d'inversors nacionals i estrangers. Els acords comercials a gran escala solen implicar la transició des de sistemes on els usos del sòl i la varietat de cultius són múltiples fins a grans extensions de terra transformades en monocultius.

Això empitjora els sistemes de vida, la seguretat i la sobirania alimentàries de les poblacions, ja que aquests acords, facilitats pels governs, no donen resultats positius per a les comunitats locals, l'ocupació ni la sostenibilitat mediambiental (Hilhorst et al., 2011; Woodhouse i Ganho, 2011).

\section{Reflexions sobre la perspectiva de gènere a l'Àfrica}

En una recerca des de la perspectiva de gènere, és important assenyalar que aquest concepte no és universal. L'anàlisi de les dinàmiques de gènere a qual- 
sevol societat o grup familiar requereix un estudi aprofundit dels contextos socials involucrats i dels diferents tipus de jerarquia. El terme womanism va ser utilitzat per primera vegada per Walker (1983) com a teoria alternativa que es distingeix del feminisme blanc a causa de l'enfocament que fa de l'experiència femenina negra. Segons Hooks (1998), la qüestió essencial rau en la impossibilitat de separar l'opressió sexista de l'opressió racial i classista. En aquesta línia, Oyewumi (2002) té punts en comú amb el womanism defensat per les negres afroamericanes, però hi afegeix que les anàlisis i les interpretacions de l'Äfrica han de començar amb l'Àfrica. El concepte de motherism es basa en la importància de la maternitat en l'experiència de les dones africanes, mentre que el concepte de stiwanism (acrònim de STIWA-Social Transformations Including Women in Africa) entén la transformació social africana com a procés integrador d'homes i dones (Mobolanle Ebunoluwa, 2009). En aquesta línia, Ekejiuba (1995) proposa la consideració de la llar de foc o de la cuina com a unitat d'anàlisi en comptes de la llar encapçalada pels homes. L'autora reforça aquesta idea a través del joc de paraules en anglès entre household ('llar') i hearth-hold ('llar de foc'). Es mostra clarament com existeix una dualitat entre la percepció externa de les dones africanes i la seva realitat quotidiana: les dones africanes són percebudes com a víctimes passives enfront del caràcter real de les dones com a agents de canvi. És aquesta llar de foc la que estructura la família i la societat. Mobolanle Ebunoluwa (2009) considera que encara hi ha feina pendent per configurar una teoria de gènere indígena africana que respongui a l'heterogeneïtat de les cultures africanes i a la importància de la família, el matrimoni i la maternitat.

\section{Conclusions}

El paper diferenciat d'homes i dones en el manteniment dels sistemes de vida propis mostra la importància de tenir en compte la perspectiva de gènere quan s'analitzen les dinàmiques socioecològiques. La dinàmica de relacions que es crea és molt rica i complexa a cadascun dels casos que s'han analitzat. La comprensió d'aquestes dinàmiques facilitarà que les polítiques de desenvolupament local que es duguin a terme siguin reeixides.

L'agricultura ha de protegir els ecosistemes i la fertilitat del sòl. Quan els boscos desapareixen, també desapareixen ecosistemes fonamentals per a l'equilibri mediambiental i la supervivència de les comunitats. Quan es perden arbres, també es perden aliments silvestres i herbes medicinals que són essencials per a la dieta i la salut de les comunitats.

Les polítiques agrícoles de les últimes dècades tenen un paper molt important en la persistència de les vulnerabilitats masculines i femenines, com també en el debilitament dels sistemes de vida. L'acaparament de terres a escala global és un nou tipus de colonialisme. L'avançament del monocultiu industrial fa pressió sobre les terres agrícoles i posa en perill el delicat equilibri ecològic i la biodiversitat. És en aquest estat de fricció entre dos estils diferents de fer agricultura que les pràctiques agrícoles de les poblacions rurals es tornen més 
valuoses. Enfront de la necessitat d'augmentar la producció agrícola i la seva accessibilitat i gestió, les pràctiques ecoagrícoles encaminades a fer créixer la productivitat per unitat de terra, com són el foment de paisatges agroforestals, la gestió dels nutrients, la recollida de l'aigua de pluja, entre d'altres, estan donant molt bons resultats, atès que complementen el coneixement local amb l'ús de tecnologia actual. Encara hi ha pocs estudis comparatius per poder avaluar plenament els avantatges relatius d'aquests enfocaments, ja que les dades sobre els impactes que els paisatges ecoagrícoles tenen sobre la producció, els ecosistemes i els mitjans de subsistència són molt difícils de mesurar d'una manera integrada (Pretty, 1999).

És necessari que l'agricultura africana serveixi, d'entrada, a assegurar l'alimentació de les poblacions autòctones, tenint en compte les especificitats pròpies de cada país. El desenvolupament rural s'ha de fer en el marc d'una seguretat alimentària reconeguda a llarg termini, a través de la protecció de les poblacions i on les inversions es realitzin per assegurar els sistemes de vida propis.

\section{Referències bibliogràfiques}

ADAmS, Alayne; CEKAN, Jindra i SAUERBORN, Rainer (1998). «Towards a Conceptual Framework of Household Coping: Reflections from Rural West Africa». Africa, 68 (2), 263-283.

AgARwal, Bina (1991). «Engendering the Environment Debate: Lessons from the Indian Subcontinent». CASID Distinguished Speaker Series, 8. Michigan State University.

Agúndez, Dolores; Houtondji, Françoise i Simeni-Tchuinte, Ghislaine (2010). «Régimen de propiedad y género en un sistema de gestión agroforestal en el norte de Benín». $7^{\circ}$ Congreso Ibérico de Estudios Africanos. Panel n. ${ }^{\circ}$ 11: «Equidad de Género: Desarrollo y Cooperación». Lisboa, setembre.

AwUMbila, Mariama i MomsEn, Janet (1995). "Gender and the Environment: Women's Time Use as a Measure of Environmental Change». Global Environmental Change, 5 (4), 337-346.

Bromley, Daniel (2008). «Formalising Property Relations in the Developing World: The Wrong Prescription for the Wrong Malady». Land Use Policy, 26, 20-27.

Bryceson, Deborah i Howe, John (1993). "Rural Household Transport in Africa: Reducing the Burden on Women». World Development, 21 (11), 1715-1728.

BunCH, Roland (2010). «La crisi de la fertilitat del sòl a l'Àfrica i l'episodi de fam que s'acosta». A: Halweil, Brian i NierenberG, Danielle (ed.). 2011 L'estat del món: Innovacions que alimenten el planeta. Barcelona: Centre UNESCO de Catalunya. Versió original: 2011 State of the World. Innovations that Nourish the Planet. Worldwatch Institute, Washington, D.C.

CARneY, Judith (1996). "Converting the Wetlands, Engendering the Environment: The Intersection of Gender with Agrarian Change in the Gambia». A: PEET, Richard i WaTTS, Michael (ed.). Liberation Ecologies: Environment, Development, Social Movements, Londres: Routledge.

CARNEY, Judith i EliAS, Marlène (2004). "La filière féminine du karité: productrices burkinabè, "éco-consommatrices" occidentales et commerce équitable». Cahiers de Géographie du Québec, 48 (133), 71-88. 
CARneY, Judith i Elias, Marlène (2006). «Revealing Gendered Landscapes: Indigenous Female Knowledge and Agroforestry of African Shea». Canadian Journal of African Studies, 40 (2), 235-267.

Chelleri, Lorenzo i Breton, Françoise (2010). «Rethinking Spatial Planning Paradigms at the Light of the Regional Ecosystem Services Frameworks». A: Resilient Cities. ICLEI ed. , Brussels.

CORTABITARTE, Gemma (1994). «Desforestació al continent africà: causes i implicacions». Studia Africana, 5, 173-180.

Costanza, Robert; D’Arge, Ralph; De Groot, Rudolph et al. (1997). «The Value of the World's Ecosystem Services and Natural Capital». Nature, 387, 253-260.

EkejIUbA, Felicia (1995). «Down to Fundamentals: Women-Centered Hearth-holds in Rural West Africa». A: BryCESON, Deborah (ed.). Women Wielding the Hoe. Oxford: Oxford University Press.

Evers, Barbara i Walters, Bernard (2000). «Extra-Household Factors and Women Farmer's Supply Response in Sub-Saharan Africa». World Development, 28 (7), 1341-1345

FEDERICI, Silvia (2004). «Women, Land-Struggles and Globalization: An International Perspective». Journal of Asian and African Studies, 39, 47-62.

Gibson, Nigel (2004). "Africa and Globalization: Marginalization and Resistance». Journal of Asian and African Studies, 39, 1-26.

GraY, Leslie i KeVANE Michael (1999). «A Woman's Field is Made at Night: Gendered Land Rights and Norms in Burkina Faso». Feminist Economics, 5 (3), 1-31.

Halweil, Brian i Nierenberg, Danielle (2010). «Un nou camí per posar fi a la fam». A: Halweil, Brian i Nierenberg, Danielle (ed.). 2011 L'estat del món: Innovacions que alimenten el planeta. Barcelona: Centre UNESCO de Catalunya. Versió original: 2011 State of the World. Innovations that Nourish the Planet. Worldwatch Institute, Washington, D.C.

Hardin, Garret (1968). "The Tragedy of the Commons». Science, 162, 1243-1248.

Hilhorst, Thea; Nelen, Joost i Traoré, Nata (2011). "Agrarian Change below the Radar Screen: Rising Farmland Acquisitions by Domestic Investors in West Africa Results from a survey in Benin, Burkina Faso and Niger». Comunicació presentada a la International Conference on Global Land Grabbing, abril de 2011, organitzada per Land Deal Politics Initiative, en col-laboració amb The Journal of Peasant Studies, Future Agricultures Consortium at the Institute of Development Studies, Universitat de Sussex.

HoOKS, Bell (1998). «Black Feminism: Historical Perspective». A: LigGings HiLls, Patricia et al. (ed.). Call and Response: The Riverside Anthology of African American Literary Tradition. Boston: Houghton Miffling Company.

Hossein, Caroline (2004). «Thinking Outside the Islamic Box: Linking Context and Credit in Muslim West Africa». Critical Half: Bi-Annual Journal for Women International, 2 (1), 29-33.

Jiggins, Janice (1989). «How Poor Women Earn Income in Sub-Saharan Africa and What Works against Them». World Development, 17 (7), 953-963.

Joireman, Sandra (2008). "The Mystery of Capital Formation in Sub-Saharan Africa: Women, Property Rights and Customary Law». World Development, 36 (7), 1233-1246.

LAAKSO, Anna; TYYNELÄ, Tapani (2006). «Non-wood Forest Benefits and Agroforestry Practices in the Fouta Djallon Highlands of Guinea». Nordic Journal of African Studies 15 (4), 579-590. 
LEACH, Melissa (1992). "Gender and the Environment: Traps and Opportunities». Development in Practice, 2 (1), 12-22.

- (1994). Rainforest Relations: Gender and Resource Use among the Mende of Gola, Sierra Leone. Londres: Edinburg University Press for the International African Institute.

LeaCH, Melissa; Mearns, Robin i SCOOnes, Ian (1999). «Environmental Entitlements: Dynamics and Institutions in Community-Based Natural Resource Management». World Development, 27 (2), 225-247.

LETTY, Brigid et al. (2010). «Els agricultors encapçalen les activitats de recerca i desenvolupament». A: Halweil, Brian i NierenberG, Danielle (ed.). 2011 L'estat del món. Innovacions que alimenten el planeta. Barcelona: Centre UNESCO de Catalunya. Versió original: 2011 State of the World: Innovations that Nourish the Planet. Worldwatch Institute, Washington, D.C.

MACKENZIE, Fiona (1993). «Exploring the Connections: Structural Adjustment, Gender and the Environment». Geoforum, 24 (1), 71-87.

Martínez Alier, Joan (2002). The Environmentalism of the Poor: A Study of Ecological Conflict and Valuation. Cheltenham: Edward Elgar.

Meinzen-Dick, Ruth; Brown, Lynn et al. (1997). "Gender, Property Rights and Natural Resources». World Development, 25 (8), 1303-1315.

Milano, Serena (2010). "Protegir la biodiversitat alimentària local». A: HaLWEIL, Brian i NiEREnBerg, Danielle (ed.). 2011 L'estat del món: Innovacions que alimenten el planeta. Barcelona: Centre UNESCO de Catalunya. Versió original: 2011 State of the World: Innovations that Nourish the Planet. Worldwatch Institute, Washington, D.C. Washington, D.C.

Millenium Ecosystem Assessment (2003). Ecosystems and Human Well-Being: A Framework for Assessment. Washington, DC: Island Press.

- (2005). Ecosystems and Human Well-Being Synthesis. Washington, DC: Island Press.

Mobolanle Ebunoluwa, Sotunsa (2009). «Feminism: the Quest for an African Variant». The Journal of Pan African Studies, 3 (1), 227-234.

Moller Madsen, Lene i Adriansen, Hanne (2004). "Understanding the Use of Rural Space: the Need for Multi-Methods». Journal of Rural Studies, 20, 485-497.

Momsen, Janet (2004). Gender and Development. Londres: Routledge.

Nelson-Fyle, Markus i Sandhu, Ruby (1990). The Impact of Animal Traction on Women. Third Workshop on the West African Animal Traction Network, del 7 al 12 de juliol. Senegal.

Oberhauser, Ann; Mandelb, Jennifer i Hapkec, Holly (2004). "Gendered Livelihoods in Diverse Global Contexts: an Introduction». Gender, Place \& Culture, 11 (2), 205-208.

Ostrom, Elinor (1990). Governing the Commons: The Evolution of Institutions for Collective Action. Cambridge University Press.

OYEWUMI, Oyeronke (2002). «Conceptualizing Gender: The Eurocentric Foundations of Feminist Concepts and the Challenge of African Epistemologies». A Journal of Culture and African Women's Studies, 2 (1), 1-6.

PORTER, Gina (2002), «Living in a Walking World: Rural Mobility and Social Equity Issues in Sub-Saharan Africa», World Development 30(2), p. 285-300.

Postel, Sandra (2010), "Produir més per cada gota» a HalWeIL, Brian; NierenberG, Danielle (ed.), 2011 L'estat del món. Innovacions que alimenten el planeta, Centre UNESCO de Catalunya, versió traduïda de l'original, 2011 State of the World. Innovations that Nourish the Planet, Worldwatch Institute, Washington, D.C. 
PretTy, Jules (1999). «Can Sustainable Development Feed Africa?: New Evidence on Progress, Processes and Impacts». Environment, Development and Sustainability, 1, 253-274.

RAZAVI, Shahra (2003). «Introduction: Agrarian Change, Gender and Land Rights». Journal of Agrarian Change, 3 (1-2), 2-32.

REIJ, Chris (2010). «Idees per afrontar el canvi climàtic i fomentar la resiliència: Inversió en arbres per mitigar el canvi climàtic». A: HALWEIL, Brian i NIERENBERG, Danielle (ed.). 2011 L'estat del món: Innovacions que alimenten el planeta. Barcelona: Centre UNESCO de Catalunya. Versió original: 2011 State of the World: Innovations that Nourish the Planet. Worldwatch Institute, Washington, D.C.

Rocheleau, Dianne i Edmunds, David (1997). «Women, Men and Trees: Gender, Power and Property in Forest and Agrarian Landscapes». World Development, 25 (8), 1351-1371.

SABATÉ, Ana (2000). "Género, medio ambiente y acción política: Un debate pendiente en la geografía actual». Anales de Geografía de la Universidad Complutense, 20, 177-191.

SChroeder, Richard i Krisnawati, Suryanata (1996). "Gender and Class Power in Agroforestry: Case Studies From Indonesia and West Africa». A: PEET, Richard i WaTts, Michael (ed.). Liberation Ecologies: Environment, Development, Social Movements. Londres: Routledge.

SEn, Amartya (1981). Poverty and Famines: An Essay on Entitlement and Deprivation. Oxford: Oxford University Press.

Sow, Papa (2000). "Ambigüités de l'accès à la terre au Sénégal: appropriation et exploitation de l'environnement rural par les 'récolteuses de sel' du Lac Rose». Studia Africana, 11, 23-38.

Walker, Alice (1983). In Search of Our Mothers' Gardens: Womanist Prose. Nova York: Harcourt Inc.

Whitehead, Ann i Tsikata, Dzodzi (2003). «Policy Discourses on Women’s Land Rights in Sub-Saharan Africa: The Implications of the Re-turn to the Customary». Journal of Agrarian Change, 3 (1-2), 67-112.

Woodhouse, Philip i GanHo, A.S. (2011). "Is Water the Hidden Agenda of Agricultural Land Acquisition in sub-Saharan Africa?». Comunicació presentada a la International Conference on Global Land Grabbing, abril de 2011, organitzada per Land Deal Politics Initiative, en col-laboració amb The Journal of Peasant Studies, Future Agricultures Consortium at the Institute of Development Studies. Universitat de Sussex.

\section{Bibliografia web}

Cercador de bibliografia sobre literatura africana femenina (The African Studies Centre, Leiden, Holanda)

www.africabib.org [Consulta: maig 2011]

Setè Congrés Ibèric d'Estudis Africans http://cea.iscte.pt/ciea7/es/index.html [Consulta: maig 2011]

The International Conference on Global Land Grabbing http://www.future-agricultures.org/index.php?option=com_contenterview $=$ article $r i d=74$ 67 \&Itemid $=980$ [Consulta: juliol 2011] 